\title{
Fouling Release Property of Polydimethylsiloxane Based Polyurea with Improved Adhesion to Substrate
}

Chao Liu, Qingyi Xie, Chunfeng Ma, Guangzhao Zhang*

Faculty of Materials Science and Engineering, Key Laboratory of Polymer Processing Engineering, South China University of Technology, Guangzhou 510640, P. R. China

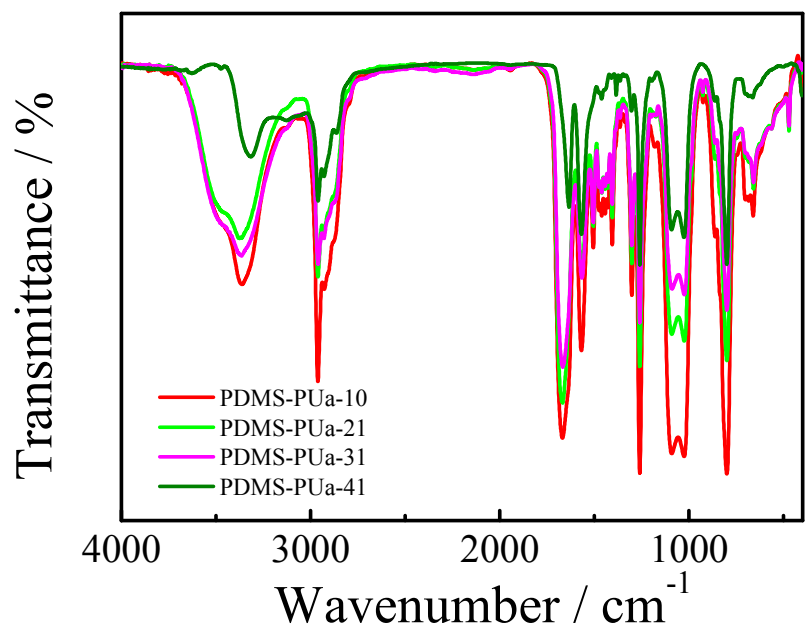

Figure S1. FT-IR spectra for PDMS-PUa-X.

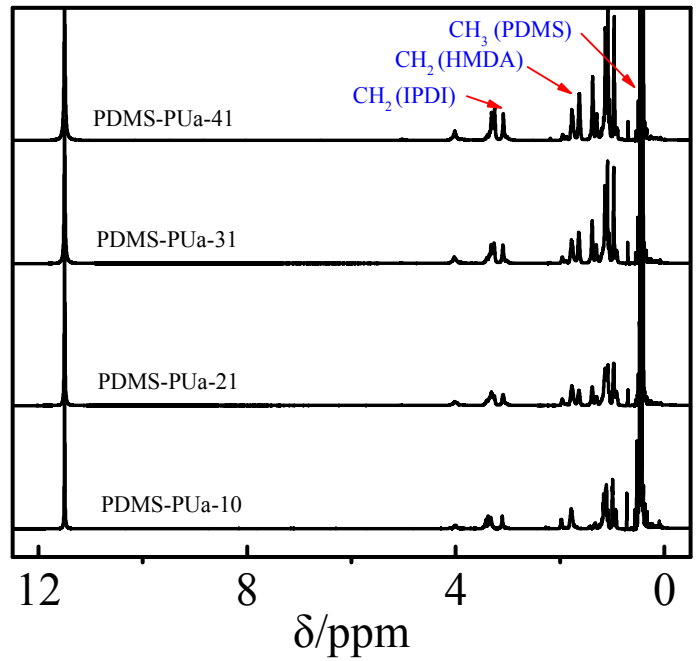

Figure S2. ${ }^{1} \mathrm{H}$ NMR spectra for PDMS-PUa-X. 
The weight percentage of PDMS (soft segment) in PDMS-PUa-x is estimated by using the following equation:

$$
W_{P D M S}=\frac{\frac{M_{P D M S} A_{P D M S}}{H_{P D M S}}}{\frac{M_{P D M S} A_{P D M S}}{H_{P D M S}}+\frac{M_{I P D I} A_{I P D I}}{H_{I P D I}}+\frac{M_{H M D A} A_{H M D A}}{H_{H M D A}}} \times 100 \%
$$

where $\mathrm{A}$ is the integration of resonances, $A_{P D M S}$ is for the methyl in PDMS (0.43 ppm, 2 per PDMS), $A_{I P D I}$ is for the methylene in IPDI (3.07 ppm, 1 per IPDI), $A_{H M D A}$ is for the methylene in HMDA (1.60 ppm, 2 per HMDA). $M_{P D M S}, M_{I P D I}$ and $M_{H M D A}$ are 74, 224 , and $114 \mathrm{~g} / \mathrm{mol}$, respectively. $H_{P D M S}, H_{I P D I}$ and $H_{H M D A}$ are the number of protons per proton-bearing group assessed (6 methyl protons per PDMS, 2 methylene protons per IPDI, 4 methylene protons per HMDA). For samples with hard segment content in feed being $10 \mathrm{wt} \%, 20 \mathrm{wt} \%, 30 \mathrm{wt} \%$ and $40 \mathrm{wt} \%$, the PDMS contents are $90.1 \mathrm{wt} \%$, $79.3 \mathrm{wt} \%, 68.7 \mathrm{wt} \%$ and $58.7 \mathrm{wt} \%$, respectively. Therefore, the hard segments contents in the polymer are $9.9 \mathrm{wt} \%, 20.7 \mathrm{wt} \%, 31.3 \mathrm{wt} \%$ and $41.3 \mathrm{wt} \%$, respectively.

Table S1. Areas of peaks in ${ }^{1} \mathrm{HNMR}$ by integration

\begin{tabular}{ccccc}
\hline Peak area & PDMS-PUa-10 & PDMS-PUa-21 & PDMS-PUa-31 & PDMS-PUa-41 \\
\hline $\mathrm{A}_{\text {IPDI }}{ }^{*}$ & 1.00 & 1.00 & 1.00 & 1.00 \\
$\mathrm{~A}_{\text {PDMS }}$ & 82.61 & 46.95 & 28.67 & 19.95 \\
$\mathrm{~A}_{\text {HMDA }}$ & 0.00 & 1.38 & 1.73 & 2.14 \\
\hline
\end{tabular}

$* \mathrm{~A}_{\text {IPDI }}$ is used as the reference.

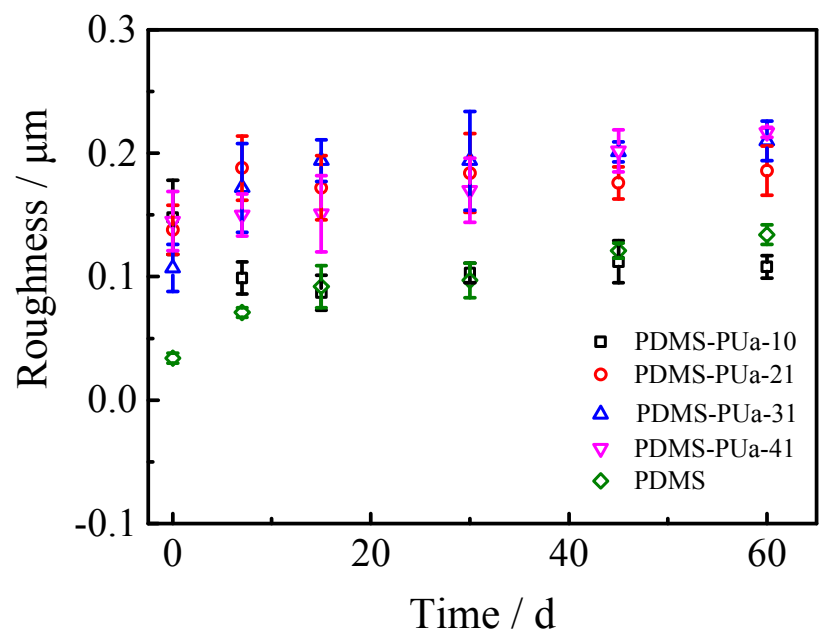

Figure S3. Surface roughness of PDMS-PUa-x coatings 
Table S2. Contact angles of PDMS-PUa-x surfaces

\begin{tabular}{cccc}
\hline Samples & Static angle $\left(^{\circ}\right)$ & Advancing angle $\left(^{\circ}\right)$ & Receding angle $\left({ }^{\circ}\right)$ \\
\hline PDMS & $115.9 \pm 0.6$ & $120.8 \pm 0.5$ & $94.3 \pm 1.8$ \\
PDMS-PUa-10 & $107.7 \pm 0.4$ & $115.2 \pm 0.9$ & $90.0 \pm 1.9$ \\
PDMS-PUa-21 & $102.6 \pm 0.5$ & $107.7 \pm 0.6$ & $90.8 \pm 0.5$ \\
PDMS-PUa-31 & $101.6 \pm 0.7$ & $106.2 \pm 0.5$ & $90.4 \pm 0.9$ \\
PDMS-PUa-41 & $100.8 \pm 0.3$ & $104.5 \pm 0.7$ & $88.5 \pm 0.9$ \\
\hline
\end{tabular}

Time

(days)

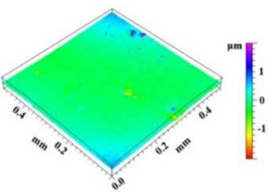

0

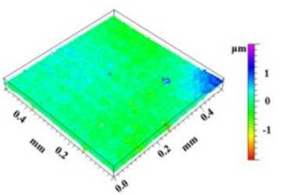

15

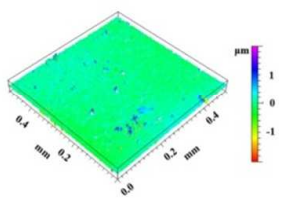

30

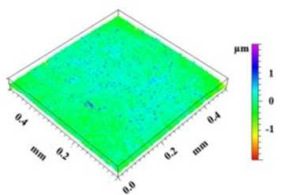

60

Figure S4. Surface topography of PDMS-PUa-x before and after immersion in artificial seawater at $25^{\circ} \mathrm{C}$, where the hard segment content is $21 \mathrm{wt} \%$. 